\title{
THE FORMS AND METHODS OF ART DISCIPLINES' TEACHING UNDER THE CONDITIONS OF DISTANCE LEARNING
}

\section{${ }^{a}$ YUDING XIE, ${ }^{\mathrm{b}}$ NATALIIA RUBLEVSKA, ${ }^{\mathrm{c}}$ MARIYA MARKOVYCH, ${ }^{\mathrm{d}}$ ZOIA MATSYSHYNA, ${ }^{\mathrm{e}}$ SVITLANA VOLSKA, ${ }^{\mathrm{f}}$ IRYNA TIUTIUNNYK}

${ }^{a}$ Ternopil National Pedagogical University named after Volodymyr Hnatyuk, Ternopil, Ukraine, ${ }^{b}$ Ternopil National Pedagogical University named after Volodymyr Hnatyuk, Ternopil, Ukraine, ${ }^{\mathrm{C}}$ Ternopil National Pedagogical University named after Volodymyr Hnatyuk, Ternopil, Ukraine, ${ }^{d}$ Ternopil National Pedagogical University named after Volodymyr Hnatyuk, Ternopil, Ukraine, ${ }^{e}$ Ternopil National Pedagogical University named after Volodymyr Hnatyuk, Ternopil, Ukraine, ${ }^{f}$ Ternopil National Pedagogical University named after Volodymyr Hnatyuk, Ternopil, Ukraine email: ${ }^{a}$ marijater@gmail.com, ${ }^{b}$ rublevnv@elr.tnpu.edu.ua, cmarijater@gmail.com, ${ }^{d}$ zoya.macishina80@ukr.net, 'egolvolus@ukr.net, ${ }^{f}$ Tyutyunnuk@gmail.com

Abstract: This article describes the development of forms and methods of art disciplines' teaching under the conditions of distance learning. The main aim of the research is to develop recommendations for the artistic disciplines' teaching by educational institutions under the conditions of distance learning. To achieve this goal during the research, the following tasks will be carried out: - substantiation of the during the research, the following tasks will be carried out: - substantiation of the
relevance of the study under the conditions of quarantine restrictions; - critical analysis relevance of the study under the conditions of quarantine restrictions; - critical analysis
of the literature on the development of the form and methods of teaching art of the literature on the development of the form and methods of teaching art
disciplines; - the features of online work, and the features of work under the conditions disciplines; - the features of online work, and the features of work under the conditions of distance learning in higher education institutions. To conduct empirical research aimed at confirming the effectiveness of the developed teaching forms, we surveyed a group of students. It allowed proving the hypothesis that distance learning can be in independent and group work, and other types of distance learning. The main direction of the devepuctional technologies within the virtual environment. The developed forms and methods of distance learning are expedient to use both in the work with full-time students and the communication using Skype, which forms the practical significance of the research.

Keywords: art disciplines, distance learning, online education, teaching methods, teaching forms.

\section{Introduction}

The COVID-19 pandemic has caused the greatest disruption of education systems in history. It affected students in more than 190 countries on all continents. In low- and below-middleincome countries, the closure rate for schools and other educational institutions reached $99 \%$. The crisis has exacerbated the already severe inequalities that have long existed in education. A large proportion of the most vulnerable children, youth, and adults are unable to continue their education. Losses in education can negatively impact decades of progress.

At the same time, it is worth noting that the crisis has spurred innovation in education. Innovative approaches, from video, radio, and TV broadcasts to the provision of homeschooling kits, have emerged to ensure the continuity of education and training. The rapid response of the world governments to provide a seamless learning experience has led to the development of distance learning solutions.

The problem of keeping people healthy has become a priority for Ukraine as well. That is why the most effective way to change the format of communication between the participants of the educational process was distance learning.

Distance learning is a universal, integral, humanistic form of learning, based on which conditions are created for students, relatively free choice of academic disciplines, teaching staff for a particular discipline (Garbich-Moshora, 2015).

The relevance of this education format is in the fact that it allows nationwide access to educational resources through the use of modern information technologies and telecommunications networks, creates conditions for citizens to exercise their rights to education (Samolyuk \& Shvets, 2013; Sydorenko et al., 2020).
If receiving basic education remotely evokes ambiguous reactions to the opinions of students, students, teachers, and scholars involved in the study of this issue, the situation with receiving a second higher education, taking additional professional development courses is quite different. The relevance of distance education, in this case, does not doubt because it allows:

- $\quad$ to study per their educational needs;

- do not limit themselves in their choice of educational institution and educational opportunities, despite their location;

- $\quad$ to use modern technologies, i.e., at the same time to learn skills that will be needed later in the workplace;

- independently plan the time and schedule of classes;

- to study in the most pleasant and productive environment, creating for oneself a favorable atmosphere;

- to receive additional education abroad when there is no possibility to go to another country.

However, the positive practice of the effectiveness of distance work is not observed in every educational institution. Besides, the problem is aggravated by the constant dissatisfaction of parents, students, and pupils themselves with the format of such work. It allows forming the main hypothesis of the study. However, distance learning in art disciplines' teaching can be effective not only theoretically but also in practice.

The solution of this form has shaped the research relevance and its purpose. The research aims to develop new forms and methods of distance learning for art disciplines' teaching, which make it more accessible and qualitative.

\section{Literature review}

Theoretical and practical aspects of distance education are actively studied by both domestic and foreign scientists. To the main scientific materials that are important for the study of this topic, we should include modern studies of foreign researchers Liang L. (2018), Vidal T. et al. (2021), Leduc D. \& Beland S. (2021), Yu S . (2019), Hermon R. (2021), Jeong D-E. (2020). The researches of Ukrainian scientists who carried out the study of the peculiarities of teaching art disciplines are also important. The most relevant at the moment are the papers by Lvova I. \& Bakhlova N. (2021), Lemeshko L. (2018), Solomakha S. (2020). The issues of teaching under distance learning conditions in Ukraine were investigated by Garbich-Moshora, O. (2015), Samolyuk N.\& Shvets M. (2013), Alexandrova E. (2010), Ponomareva A. (2011), Sadirova G. (2021), Shtykhno L. (2016) and others.

Recently, a lot of attention has been paid to distance learning. It is at the center of scientific circles' attention. Current trends suggest that research in this area will continue. Nowadays, the theoretical, methodological, and methodical problems of distance learning are being studied by domestic and foreign scientists. In particular, much attention is paid to the issues of art disciplines' teaching in a distance learning environment.

The problem of studying artistic disciplines online was considered by Lvova I. \& Bakhlova N. (2021) in their research paper. The authors traced the changes in the problems of teaching and made analytical conclusions about how students' attitudes to the process of distance learning have changed. In their opinion, teaching creative disciplines cannot be fully implemented online.

Lemeshko L. (2018), in her article, focused on the need to develop and use electronic textbooks in the educational process in the study of artistic disciplines. In her opinion, the electronic textbook is not an analogue of the printed edition; it, rather, acts as a kind of educational environment. In addition to text information, it has a large amount of multimedia material, allows 
working with remote resources, and quickly moves to different parts of the publication.

The necessity of introducing innovative educational technologies in the educational process of master's training to form the professional competence of art teachers is considered in the paper by Solomakha S. (2020).

The features of the aesthetic culture of the art disciplines' teacher considered in the research by Liang L. (2018). He identified the determinants of successful training of future teachers of disciplines in higher education institutions. He also revealed the theoretical basis for understanding the meaning of the phenomenon "aesthetic culture of an art disciplines' teacher," defined the content of the concepts "culture," "aesthetic culture," "cultural training, aesthetic competence".

Vidal T. et al. (2021), in their research, considered the introduction of virtual reality (VR) technology to improve student performance. They have proposed new instructional techniques that incorporate VR and gamification techniques in the development of video game projects.

Based on theoretical and empirical findings from art teachers in Canada and Europe, in Perspectives on the Assessment of Arts Learning in Higher Education, Leduc D.\& Beland S. (2021) explored how arts education can be effectively and fairly assessed in the context of higher education. They examined a variety of assessment methods in music, visual and plastic arts, performing arts, design, fashion, dance, music and illustrated how knowledge, competencies, skills, and progress could be viable and fair assessments.

A new basic model of learning for the arts disciplines in the age of information was examined by Yu F. (2019). According to him, it is needed in the general background of the new creativeentrepreneurial circuit, and learning should be done from a core of "learning to know, developing aesthetic analysis, and developing the logic of the visual arts."

Hermon R. (2021), in her article, examines new online experiments in alternative art education as examples of parainstitutional practices. Her goal is to demonstrate that the boundaries of institutional practice are gracious spaces for questioning the terms of conversation when exploring institutional processes and parameters as part of an ethically engaged project that seeks more inclusive and diverse art worlds.

In his review, Lierse S. (2015) concluded after research that distance education had become the best learning method for many educators seeking professional degrees.

The Korean scholar Jeong D-E. (2020) conducted a study aimed at observing art education through online classes through the Crown Crisis. According to him, changing the learning environment through new media requires a learning method suitable for students. Media literacy must be fostered to read new media. Artistic online education through digital media deserves research because it shows the possibility of configuring an individualized curriculum.

\section{Methodology}

While exploring the problem of the latest educational trends in the educational organization of higher education in today's challenges, we used several scientific research methods. One of the key methods at the initial stage of the research was the method of literary analysis. It allowed us to find out the content of the main concepts of our research, including educational trends, informatization of educational process in higher education, information and communication technologies of education, trendspotting, visualization, networking, networking, etc. The inductive, deductive, and logical methods allowed to consistently dissect the research material, analyze key aspects, and move from the individual to the general. The use of the comparison method allowed us to compare the views of domestic scientists on the problem of our study. While using the synthesis method, the practical and applied aspects of ICT use in the organization of distance format educational process in higher education were identified, including the features of effective use of individual means of computer technology.

For empirical research, an experiment was conducted among students and the Lviv National Academy of Arts. Sixty students took part in it. While selecting the control and experimental groups for the pedagogical experiment, we took into account their quantitative and qualitative components and the level of their learning achievements in artistic disciplines.

During the classes in the control groups, we used traditional teaching methods. In the experimental group, a distance component was used both in classes, using ICT, special learning platforms for online learning, and in the study of artistic disciplines remotely.

During the research, we established the criteria and indicators by which we tested the feasibility and effectiveness of the distance component in the full-time learning form:

- learning achievements. Learning achievements were determined by the initial, average, sufficient, high levels;

- cognitive interests of students, the level of which was established by the coefficient of the inconsistency of time perception

- the effectiveness analysis was carried out according to the results of initial, ongoing, and final testing.

\section{Results}

The main forms of distance discipline teaching are described in the Regulations on Distance Learning (2013). Accordingly, the educational process of distance learning is carried out in the following forms: independent work; tutorials; practical training (in HEIs); vocational and practical training (in vocationaltechnical schools); control measures. The main types of educational activities in the distance learning form are: lecture, seminar, lesson, practical training, laboratory classes, consultations, and others, developed under the features of the discipline.

\section{Elaboration of forms and methods for art disciplines' lectures}

Conducting lectures on artistic disciplines in conditions of distance learning has its peculiarities. It is subject to the provisions, which are related to the classes in the traditional form of education but differs from them by the specifics of the applicant-teacher interaction.

The work with e-learning courses happens under the control of the teacher by using distance learning technologies.

The teacher independently chooses an online platform convenient for him and the students or students, which will be used to conduct lectures on a particular discipline. The most popular platforms include:

- Moodle distance learning system;

- Google Classroom platform;

- Zoom video conferencing App;

- $\quad$ Skype App;

- Edmodo web App.

Such popular platforms as Coursera, Khan Academy, edX, iTunes U, Udemy are used abroad.

Elaboration of forms and methods for organizing independent work while teaching art disciplines

The self-organization of independent work is one of the main features of distance education. In distance learning, pupils and students move away from the conventional education system, as they learn a significant part of the training 
material without a teacher. It requires from them more independence and clear organization of the working day. A special responsibility rests on the teacher because active independent work of students is possible only with serious and sustained motivation. The student must see the usefulness of the work performed. If in traditional education a teacher spent most of his time giving lectures, education in a distant format is different in many ways. In particular, the use of the Internet, with a wide database, allows diversifying the educational materials used to organize learning activities of students and pupils, taking into account their characteristics. The Internet has opened up new opportunities for applicants for education, who can use it to find almost any information. Many sources are offered in English, so its knowledge is very relevant in today's world.

Elaboration of forms and methods for organizing sightseeing tours as a form of studying art disciplines

Virtual tours are an effective form of distance learning. They allow you to diversify and make interesting and, consequently, more effective educational processes, help to implement the principles of clarity and scientific learning, contribute to the development of observation, skills of independent work of students and pupils (Alexandrova, 2010). The virtual tour is a software and information product designed for the built-in presentation of video, audio-graphic and textual information. The multimedia panoramic photo, in contrast to the video or conventional series of photographs, has interactivity. During the interactive tour, you can zoom in and out of any object, look up and down, look around, examine in detail the panorama of the object being studied or the individual details of its interior. It is also possible to move from one panorama to another, for example, to walk around the museum halls, etc. Without leaving the classroom or classroom, you can walk around the entire object from the inside and even examine it from the outside. A virtual tour is a specific form of cognition, allowing for a considerable amount of information. It forms the means of analytical activity: comprehensive perception of the object, observation, study, research, as well as increases interest in the work and provides more in-depth and lasting assimilation of the material (Ponomareva, 2011).

\section{Elaboration of forms and methods of group work organization}

Working in groups is one more important condition for effective distance learning. In the digital world, teamwork skills are needed, both face-to-face and distance learning. Group work also helps to increase motivation and communicate at a distance. Other benefits of group work include increased comprehension of material, logical and reasonable group work done, and an increase in out-of-the-box solutions.

For work in groups to be productive, three factors must be considered:

- $\quad$ each member of the group should understand the purpose of the activity;

- distribution of responsibility between each member of the group;

- $\quad$ precise time limits must be set, i.e., the work-in-groups rules must be established.

Digital tools which help to organize group work are important. Digital tools essentially for group work already exist quite a lot. By this time, we are all used to working in the cloud, and cloud technology allows us to work on collaborative documents, collaborative presentations, shared spreadsheets, collaborative mapping, working on a timeline, and online whiteboards (Sadirova, 2021). Google Docs, Google Table, and Google Presentation tools should also be included.

Thus, distance learning is a major challenge for all participants in the educational process - educators, teachers, students, students, and their parents. It requires all the attributes typical of face-to-face learning. These are group discussions, collective discussion of the material, live communication, etc. To provide a full-fledged learning process at a distance in addition to the technical tools, school teachers and university professors have mastered several professional and personal competencies. They are necessary for interest, organization of students at the initial stage, and retention of their attention. However, this has become insufficient: the role of parents has rapidly increased in the distance learning environment, as it is difficult to demand absolute discipline and concentration from students.

It is especially problematic for teachers of art subjects to switch to new teaching technologies. It happens due to the subject specificity, which did not previously assume the use of information technology. Today teachers have mastered the distance learning platforms quite quickly. Teachers of the older generation have mastered computers. The teachers, who had the necessary technical capabilities, are mostly working with the Google Classroom App, which greatly simplifies the organizational aspects of training. Some recorded and downloaded to disk short video explanations of lessons in a familiar format to which students could ask specific questions. Phone calls and voice messages have become a common practice. Each educator uses the most convenient and easy-tounderstand tools, making sure that the majority of students have access to them afterward.

It is important to note another promising learning tool - virtual technologies. Virtual reality is one of the perspective educational methods offered by modern information technology. Nowadays, in domestic educational institutions, it is difficult to imagine a virtual reality in the educational process. However, education is one of the most common areas of this technology development. That is why those educational institutions, which will allocate resources to obtain such technology, will be able to organize a more interesting and high-quality educational process.

The main advantages of this technology for teaching artistic disciplines are:

- visualization (thanks to the use of 3D graphics, there is an opportunity to show chemical processes in detail down to the atomic level);

- involvement (with the help of virtual reality, we can change the scenarios, influence the course of the experiment, or solve problems playfully and understandably);

- focusing (the virtual world allows you to focus completely on the material and not be distracted by external stimuli);

- virtual classes (the feeling of one's presence in the depicted world is the main feature of virtual reality).

Classes with the use of modern technology are of great interest. As a result, learning motivation and the activity of students/pupils are enhanced (Trach, 2017).

Thus, digital technologies of distance learning of artistic disciplines have enough forms, methods, and tools that would raise the level of education. To date, being under quarantine constraints, the experienced have the field to carry out empirical research and the opportunity to conduct experiments that would generally confirm the hypothesis that distance learning can be effective.

The main purpose of the experimental part of this study was to confirm the effectiveness of distance learning in parallel with full-time. The results of the initial testing are shown in Table 1 .

Table 1 - The results of the initial testing of students

\begin{tabular}{|c|c|c|c|c|}
\hline Levels & \multicolumn{2}{|c|}{ Experimental group } & \multicolumn{2}{c|}{$\begin{array}{c}\text { Control } \\
\text { group }\end{array}$} \\
\hline 2 & 2 & 6,7 & 3 & 10.0 \\
\hline 3 & 7 & 23,3 & 8 & 26.7 \\
\hline 4 & 12 & 40,0 & 12 & 40.0 \\
\hline 5 & 9 & 30,0 & 7 & 23.3 \\
\hline
\end{tabular}

Source: Developed by the authors. 
The analysis of Table 1 shows that the majority of the surveyed students, both experimental and control groups, have good knowledge of art disciplines. They correspond to the average and sufficient levels:

1. Experimental class - $63.3 \%$;

2. Control class $-66.7 \%$.

The sufficient level of students' learning achievements encourages us to expand the course and the inclusion of a distance component in the learning process. It should intensify cognitive activity and improve the quality of learning.

The next stage of our research was to develop distance learning courses in art disciplines and place them on Moodle, eLearning Server, Blackboard. Our research was focused on the sufficient provision of learning material for the students in the experimental group. After studying each topic, students in both groups were tested. The results of the second testing are presented in Table 2.

Table 2 - Students' test results on the effectiveness of using distant art courses using Moodle, eLearning Server, and Blackboard

\begin{tabular}{|c|c|c|c|c|}
\hline Levels & \multicolumn{2}{|c|}{ Experimental group } & \multicolumn{2}{c|}{ Control group } \\
\hline 2 & 2 & 6.7 & 3 & 10.0 \\
\hline 3 & 6 & 20.0 & 9 & 30.0 \\
\hline 4 & 12 & 40.0 & 11 & 36.7 \\
\hline 5 & 10 & 33.3 & 7 & 23.3 \\
\hline
\end{tabular}

Source: Developed by the authors.

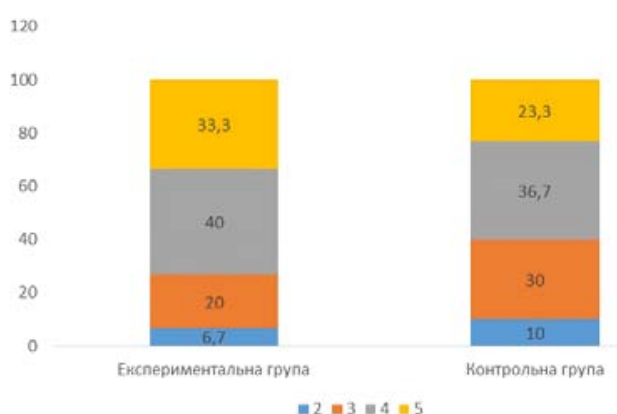

Figure 1. - The diagram of students' learning achievements in the experimental and control groups

Source: Developed by the authors.

The data analysis in Table 2 shows the following results of our experiment:

Students in the experimental group who studied the topic with the involvement of distance learning had higher achievements (73.3\%) than students in the control group (66.7\%) who studied the same learning material. The results of learning achievements with the involvement of distance learning component can be explained by the fact that distance learning allows you to expand the learning material and direct it to the development of cognitive activity and creative abilities of students, allows you to increase their level of independence, the overall success in learning artistic disciplines.

Thus, the introduction of distance learning into the educational process while studying art disciplines is more effective than the traditional form of learning.

\section{Discussion}

Today, the distance learning issue has become the object of active discussions among educators, politicians, parents, and students. In particular, representatives of the authorities, scientists, journalists, and direct participants in the educational process have different positions on this issue. Thus, according to Hryshina Y. (OP, 2020), the need to develop online education in Ukraine should not be denied, but a mixed system of education would be more effective and efficient. In turn, the principal of one of Kyiv's schools Dmitry Loza, notes that there are no clear tools for the distance learning introduction.

The same opinion is held by Sovsun I., the former Deputy Minister of Education, who notes that distance education needs several shortcomings, correcting of which requires corrective programs both at school and higher education institutions level.

At the same time, the teaching of art, as well as any other disciplines in a distance learning environment, has many advantages, among which we can note:

1. Increase in students' free time.

2. Isolation of students from each other (which is an advantage during epidemics).

3. Possibility to study at any time.

4. On-the-job learning.

5. Mobility.

6. Passing exams in a relaxed atmosphere.

7. Individual approach.

8. Learning in a relaxed atmosphere

9. Virtuous testing of knowledge by teachers.

Thus, today there are quite significant advantages of teaching artistic disciplines under conditions of distance learning, but at the same time, there are also disadvantages. Many researchers (Donetsk Law Institute of Ministry of Internal Affairs of Ukraine, 2020) consider that one of the negative aspects of distance learning is the lack of personal communication with the teacher, as well as communication with other students. Nowadays, this problem has many solutions - e-mail, telephone, video conferencing programs, etc. Sometimes you don't have to be around to be able to communicate in person. Other disadvantages include:

1. The need for a strong motivation to learn.

2. Increased time spent on communication between the teacher and the educational seeker.

3. Loss of interest in learning.

4. The lack of student identification.

5. Lack of practical skills.

6. Communication skills development

7. The possibility of unfavorable passing the control of learning among students.

Distance learning is an effective complement to traditional forms of education. One can say that it is an effective means of solving its urgent problems. While learning artistic disciplines, distance education provides students and pupils with access to nontraditional information sources. It provides unlimited and new opportunities for creativity, as well as the consolidation of various professional skills. In turn, teachers can implement fundamentally new forms and methods of learning. The development of distance learning in the system of Ukrainian education will continue and improve with the development of Internet technologies, as well as with the support of public institutions that will invest in improving the technological equipment of educational institutions (Shtykhno, 2016).

\section{Conclusions}

According to the empirical research results, we concluded that the students in the experimental group, who studied the topic using distance learning, had higher achievements than the students in the control group, who studied the same study material. This result was achieved since the teachers of art disciplines of Lviv National Academy of Arts placed their lectures on art on the platforms Moodle, eLearning Server, Blackboard. The research results confirmed the hypothesis that distance learning in art disciplines could be effective. It happens because the students are using all the advantages of distance learning, in particular:

- the possibility of learning at any convenient time; 
- the possibility of repeated listening and receiving more extensive information. Because of that, students were able to show better rates of information assimilation.

At the same time, to improve the forms and methods of distance learning of art disciplines, it was proposed to use special tools to improve the lectures, group studies, independent work, etc. A separate emphasis was placed on virtual reality and its significance in the educational process, a promising direction for improving the distance learning of art subjects.

Even though in some cases the issue of distance education shows high indicators of its quality, today this issue remains the most controversial, because the organization of quality education depends on the work of teachers in this direction, on the technical equipment of higher education institutions and teachers in particular, on the state support for the development of innovative programs

\section{Literature:}

1. Alexandrova, E. (2010). Virtual tour as one of the effective forms of organization of the educational process during the literature lesson. Literature at school.

2. Arguments "for" and "against" in distance learning (2020). OP.UA. URL: https://op.ua/news/osvita-v-ukraini/argumenti-zai-proti-v-distanciynomu-navchanni

3. Distance Learning. Advantages and disadvantages (2020). Donetsk Law Institute of the Ministry of Internal Affairs of Ukraine. URL: https://www.dli.donetsk.ua/news/2020-06-04-3

4. Garbich-Moshora, O.R (2015). Introduction of distance learning in the educational process for the training of information technology specialists. Information Technologies and Teaching Aids, 1 (45), pp. 93-105.

5. Hermon, R. (2021). Enmeshed in the Borders: The ParaInstitutional Practices of Alternative Arts Education Online. Research Refusal, 10(1). URL: https://aprja.net/article/view/128187. DOI: https://doi.org/10.7146/aprja.v10i1.128187

6. Jeong, D-E. (2020). Online Art Education and Post Art Education Discourse - Case Study on Online Art Education. Journal of Research in Art Education, 21(3), pp.67-94. DOI: https://doi.org/10.20977/kkosea.2020.21.3.67

7. Leduc, D., Beland, S. (2021). Perspectives on Learning Assessment in the Arts in Higher Education: Supporting Transparent Assessment across Artistic Disciplined.URL: https://www.taylorfrancis.com/books/edit/10.4324/97810031983 07/perspectives-learning-assessment-arts-higher-education-dian e-leduc-s\%C3\%A9bastien-b\%C3\%A9land. DOI: https://doi.org $/ 10.4324 / 9781003198307$

8. Lemeshko, L. (2018). Electronic handbooks in students' support in mystic disciplines. Mystery of the Holy Spirit, 4 (90). URL: http://artedu.com.ua/index.php/adm/article/view/22. DOI: https://doi.org/10.32405/2308-8885-2018-4-39-43

9. Liang, L. (2018). Particularities of aesthetic culture of the teacher of artistic disciplines. Ariel University, 9. URL: https://pdpu .edu.ua/doc/cult_center/israel/sbornik.pdf. DOI: http://dx.doi.org/10.24195/2218-8584-2018-9-136-140

10. Lierse, S. (2015). Preparing arts educators online for the teaching profession: Connecting a creative community. In Proceedings of 10th Asia-Pacific Symposium for Music Education Research: Music Education for the Future Generation 11. Lvova, I., Bakhlova, N. (2021). Distance learning: Artistic disciplines in expectations and results. SHS Web of Conferences, 113(2). URL: https://www.researchgate.net/publication/352740183_ Distance_learning_Artistic_disciplines_in_expectations_and_results. DOI:https://doi.org/10.1051/shsconf/202111300062

12. On approval of the Regulations on distance learning. MES of Ukraine; Order, Regulations of 25.04.2013 № 466

13. Ponomareva, A. (2011). Virtual tour as a form of education for younger students. Scientific search, 2 (3). URL: https://kerc htt.ru/uk/virtualnye-ekskursii-v-uchebno-vospitatelnom-prostra nstve-virtualnaya/

14. Sadirova, G. (2021). How to effectively organize group work in distance learning mode. Young Scientist, 23 (365), pp. 330-331. URL: https://moluch.ru/archive/365/81916/
15. Samolyuk, N., Shvets, M. (2013). Relevance and problems of distance learning. New pedagogical thought, (1) 1, p.193. 16. Shtykhno, L. (2016). Distance learning as a promising area of modern education. Young Scientist, 6 (33), pp.489-493.

17. Solomakha, S. (2020). Art-pedagogical workshop in master's training of future teachers of art disciplines. Art education: theory, history, methods, 21. URL: http://aesthe tethicpedaction.pnpu.edu.ua/article/view/218107. DOI: https://do i.org/10.33989/2226-4051.2020.21.218107

18. Sydorenko N., Denysenko V., Borisenko N., Hrytsenko I. (2020). Formation of professional competencies of primary school teachers using ICT. Revista Tempos E Espaços Em Educação, 13(32), 1-17. https://doi.org/10.20952/revtee.v13i32. 14965

19. Trach, Yu. (2017). VR-technologies as a method and means of learning. ISSN Online: 2312-5829. Educational Discourse, 34, pp.18-19.

20. Vidal, T., Navarro, I., Sánchez, A., Valls, F., Giménez, L., and Redondo, E. (2021). Virtual Reality for enhanced learning in artistic disciplines of degree of video games. 16th Iberian Conference on Information Systems and Technologies (CISTI), pp. 1-5. DOI: https://doi.oeg/10.23919/CISTI52073.2021.9476656

21. Yu, F. (2019). A New Basic Teaching Mode for Artistic Disciplines under the Information Age. 14th International Conference on Computer Science \& Education (ICCSE), pp. 212-215. DOI: https://doi.org/10.1109/ICCSE.2019.8845428

Primary Paper Section: A

Secondary Paper Section: AM 